\title{
Polymer-Scaffolded Synthesis of Periodic Mesoporous Organosilica Nanomaterials for Delivery Systems in Cancer Cells
}

\author{
Mohamed F. Attia, ${ }^{a *}$ Roman Akasov, ${ }^{b, c}$ Frank Alexis, ${ }^{d}$ and Daniel C. Whitehead ${ }^{a *}$
}

Corresponding authors:

Daniel C. Whitehead: dwhiteh@clemson.edu

Mohamed Attia: mattianrc@gmail.com

${ }^{a}$ Department of Chemistry, Clemson University, Clemson, SC, 29631, USA

${ }^{b}$ National University of Science and Technology «MISIS», Leninskiy Prospect 4, 119991

Moscow, Russia

'I.M. Sechenov First Moscow State Medical University, 119991, Trubetskaya str. 8-2, Moscow,

Russia

${ }^{\text {d} S c h o o l ~ o f ~ B i o l o g i c a l ~ S c i e n c e s ~ a n d ~ E n g i n e e r i n g, ~ Y a c h a y ~ T e c h, ~ S a n ~ M i g u e l ~ d e ~ U r c u q u i ́, ~ E c u a d o r ~}$ 100650

\section{Contents:}

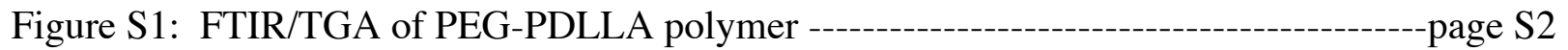

Figure S2: FTIR analysis of cargo loaded PMO nanoparticles------------------------page S3

Figure S3: XRD of CTAB----------------------------------------page S4

Figure S4: Standard Curves/UV-vis spectra of anticancer drug models-----------------page S5

Figure S5: Release of DOX cargos from PMO NPs via pH-trigger-------------------page S6

Figure S6: Cell viability studies of cargo-free PMO NPs on MCF-7 cells----------------page S7

Figure S7: Cell viability studies of DOX-loaded PMO NPs (U-87 MG/MCF-7 cells)-----page S8

Figure S8: Uptake of PMOs co-loaded with DOX-RHD in MCF-7 cells---------------page S9

Figure S9: CLSM of U-87 MG cells incubated with PMO3-DOX-RHD--------------page S10

Figure S10: Uptake of PMO3-DOX-RHD in MCF-7 and U-87 cells----------------page S10

Figure S11: Uptake of PMO1-DOX in MCF-7 cells----------------------------page S11

Figure S12: Confocal microscopy images of MCF-7 cells with free DOX----------------page S12 

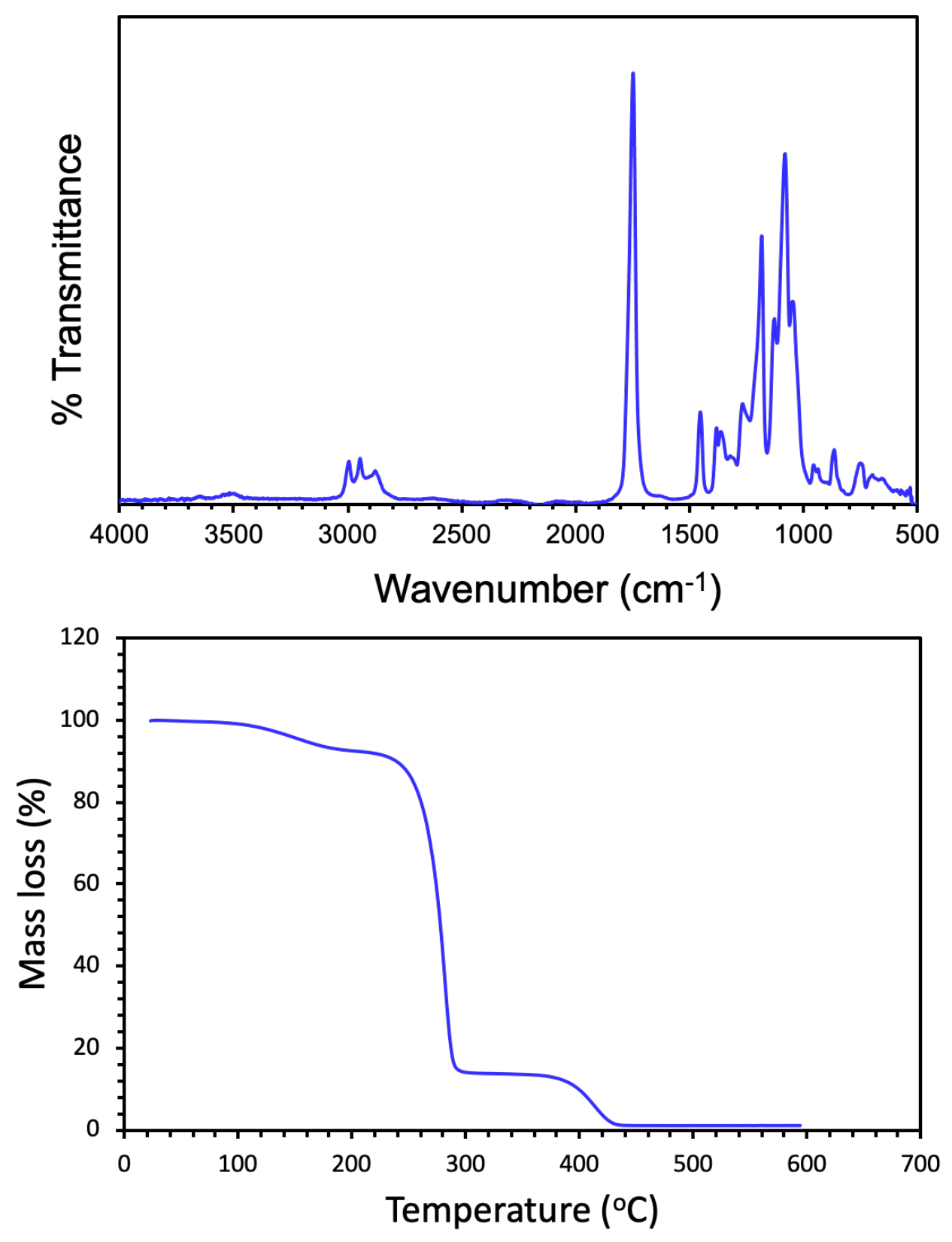

Figure S1: FT-IR spectrum (top) and TGA analysis (bottom) of the synthesized PEG-PDLLA polymer. 


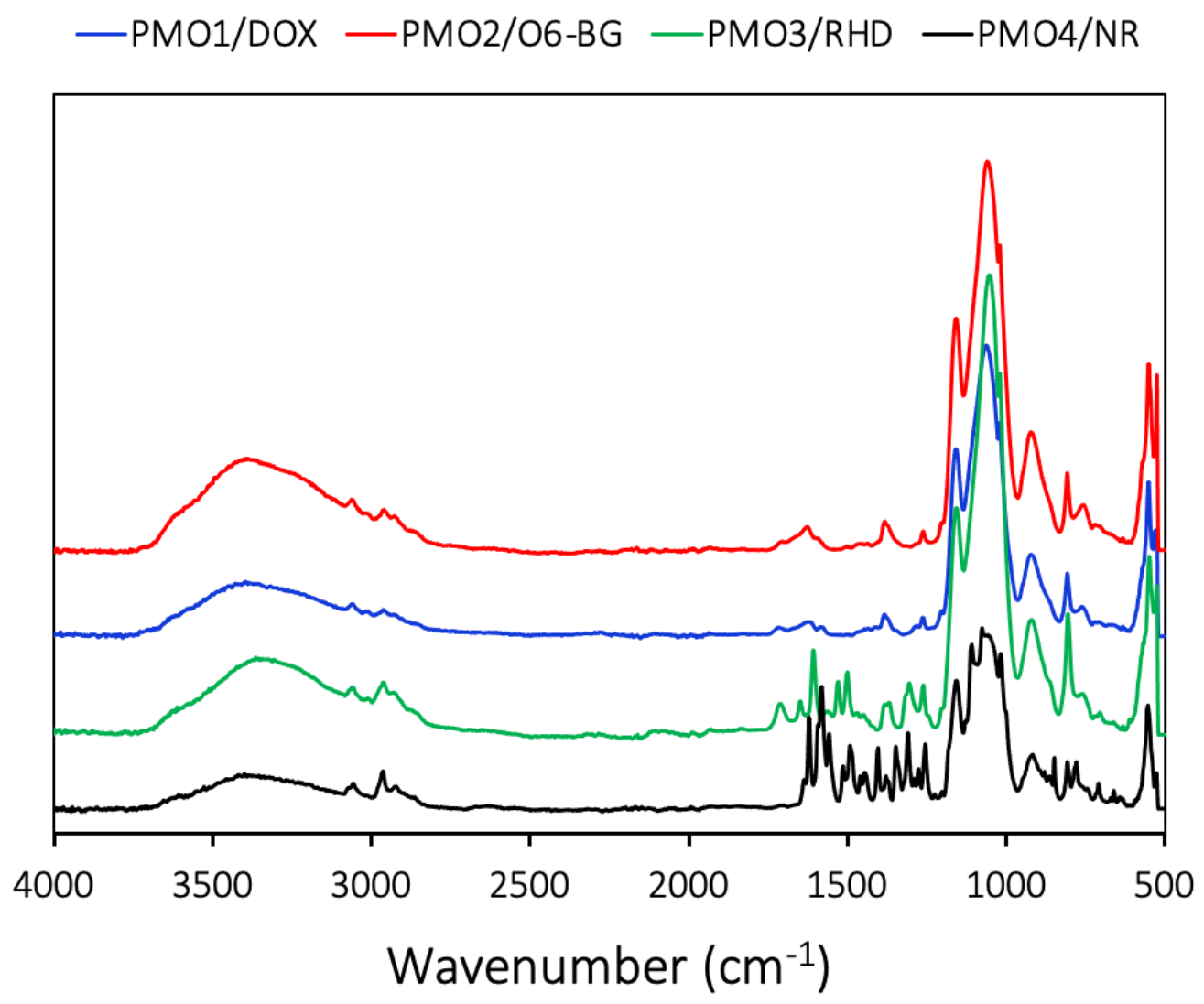

Figure S2: FTIR analysis of cargo loaded PMO nanoparticles. 


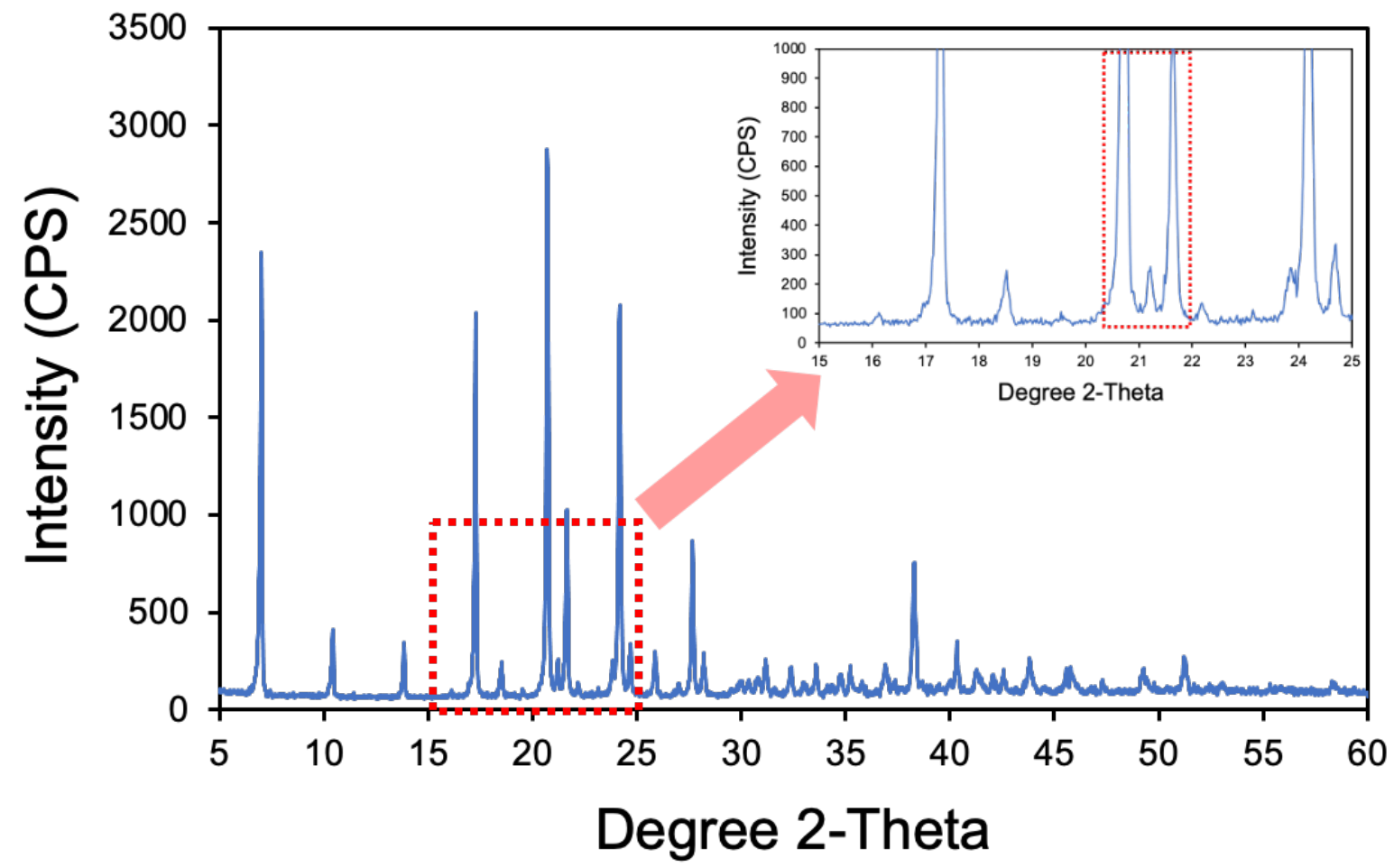

Figure S3: XRD of CTAB material as control to be compared with developed PMO nanoparticles. 
(a1)

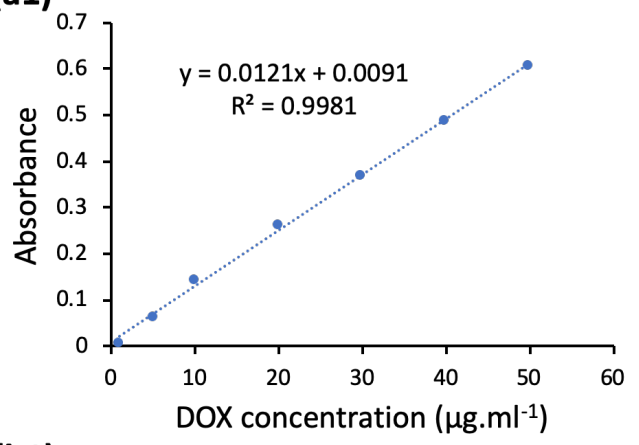

(b1)
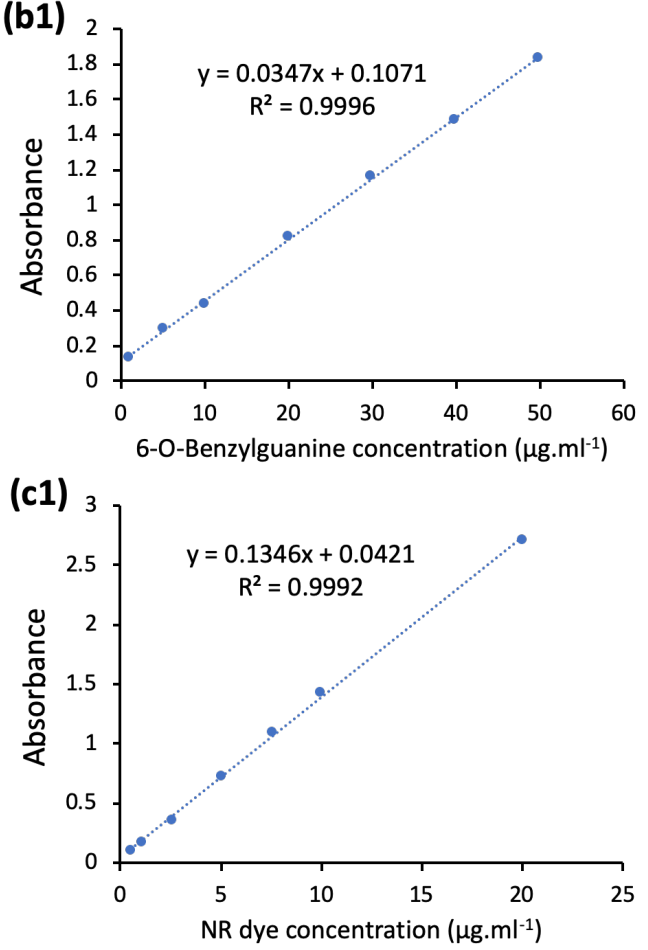

(d1)

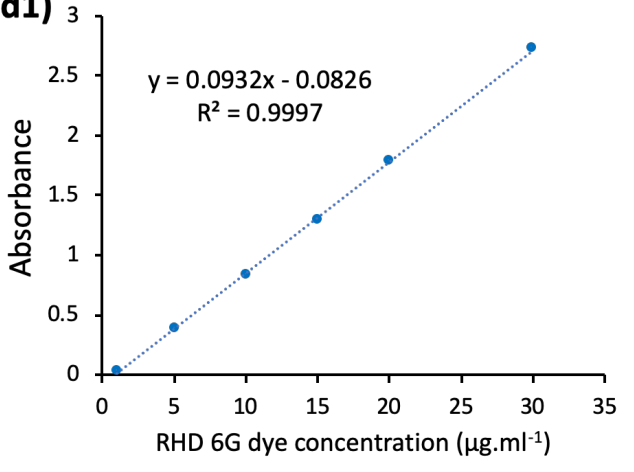

(a2)

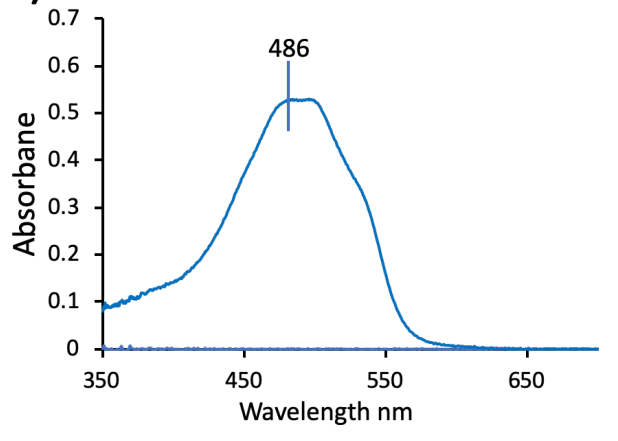

(b2)

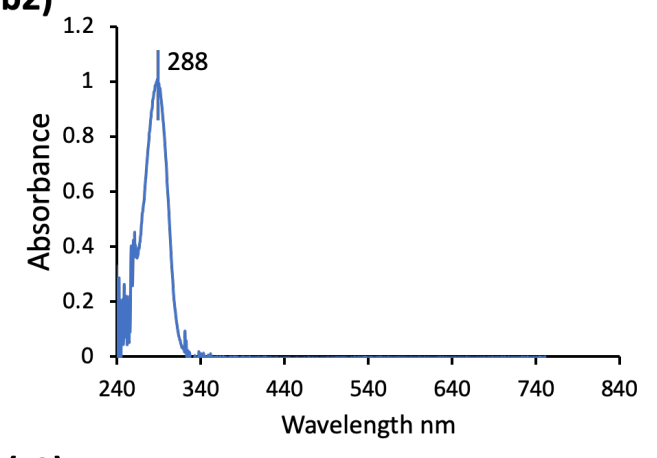

(c2)

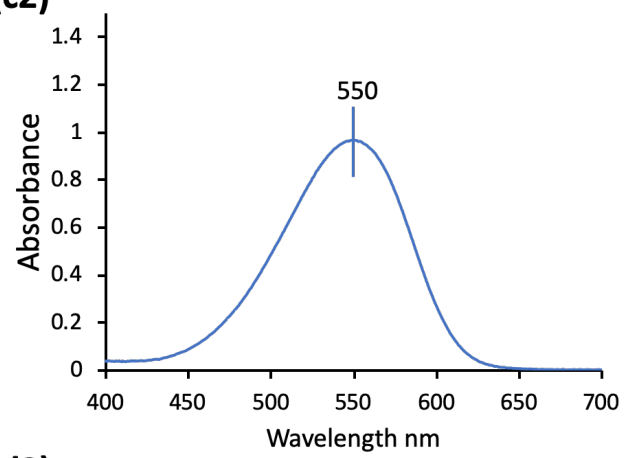

(d2)

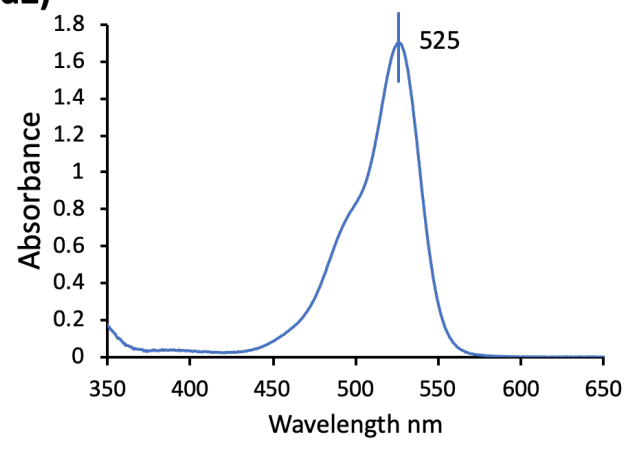

Figure S4: Standard curves and UV-vis absorption peaks for hydrophilic/hydrophobic anticancer drug models: Doxorubicin hydrochloride $(\mathrm{DOX} \bullet \mathrm{HCl})$ in $\mathrm{DI}$ water adjusted at $\mathrm{pH} 7.4$, (a1 and a2), and 6-O-Benzylguanine in DMSO (b1 and b2). Hydrophilic/hydrophobic fluorescent dye model: Nile red dye in DMSO (c1 and c2), and Rhodamine 6G dye in DI water adjusted at $\mathrm{pH}$ $7.4(\mathrm{~d} 1$ and $\mathrm{d} 2)$ 

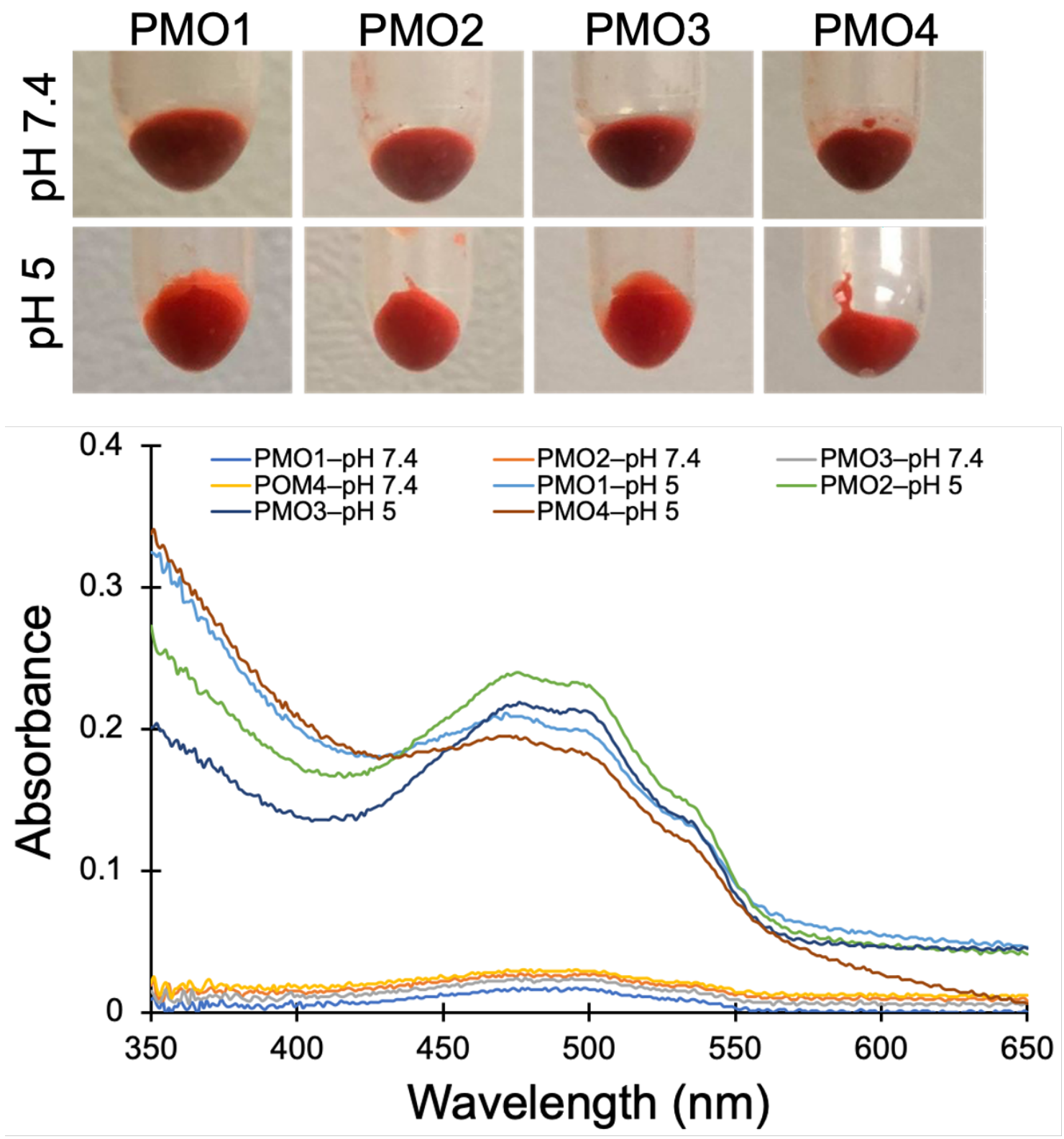

Figure S5. Release of DOX cargos from PMO NPs via pH-trigger. UV-Visible spectra of the supernatant displayed on the photographs before $(\mathrm{pH}$ 7.4) and after $(\mathrm{pH} 5)$ the addition of $\mathrm{HCl}$ aliquots. 


\section{$24 \mathrm{~h}, \mathrm{MCF}-7$ cells}

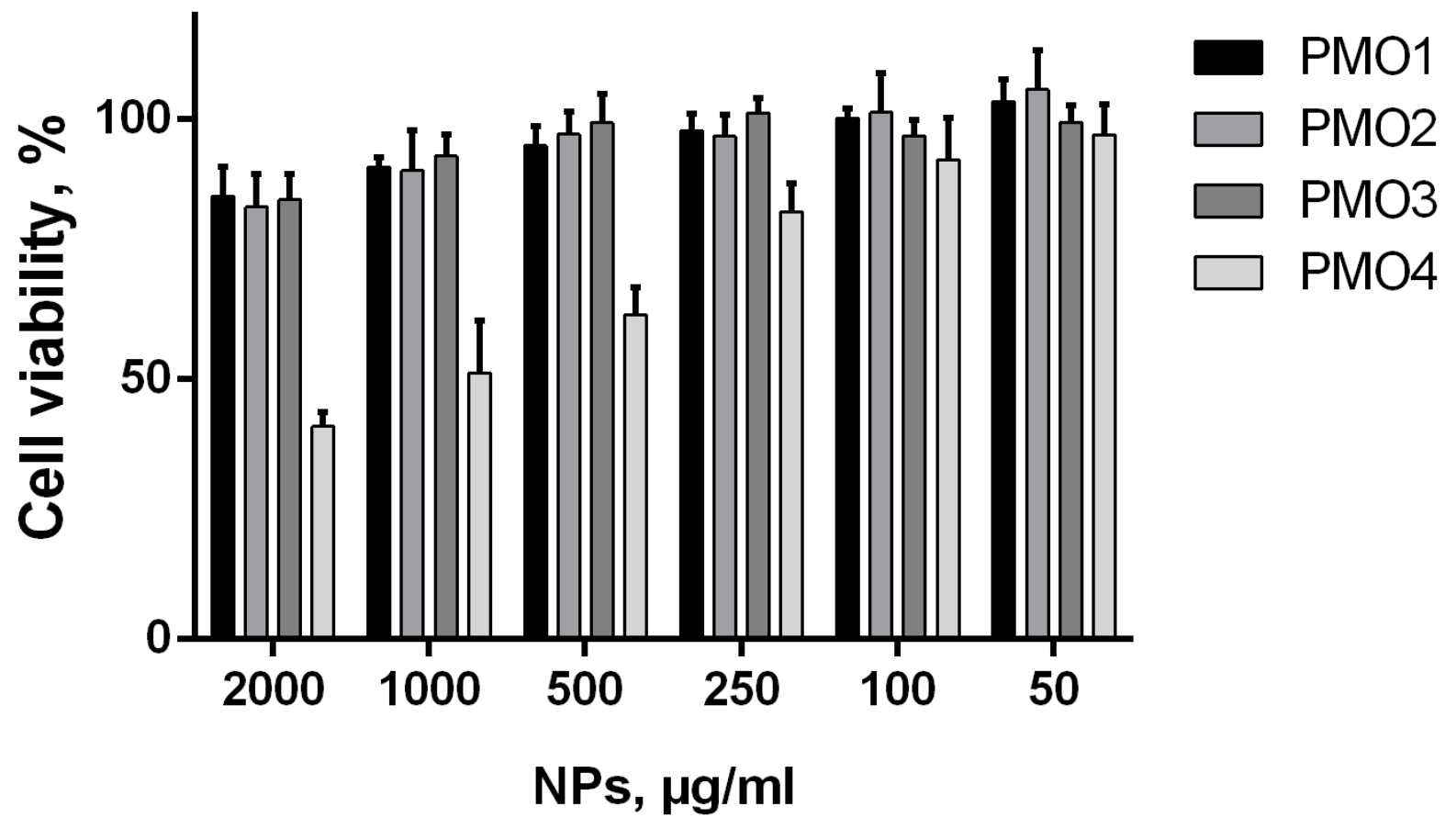

Figure S6: Cell viability studies of cargo-free PMO NPs on two MCF-7 cells incubated for $24 \mathrm{~h}$. Cells without any treatment were used as controls and taken as $100 \%$. MTT assay, the data are the mean \pm SD from at least three replicates 
U-87 MG cells

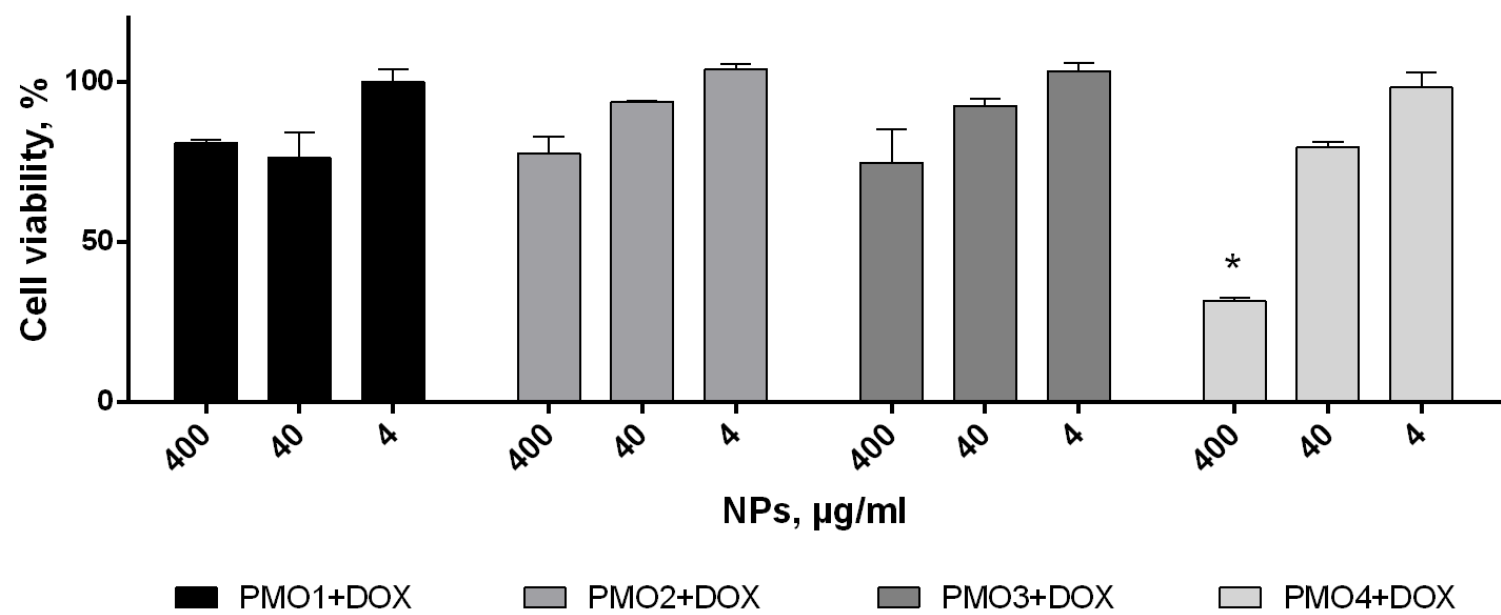

MCF-7 cells

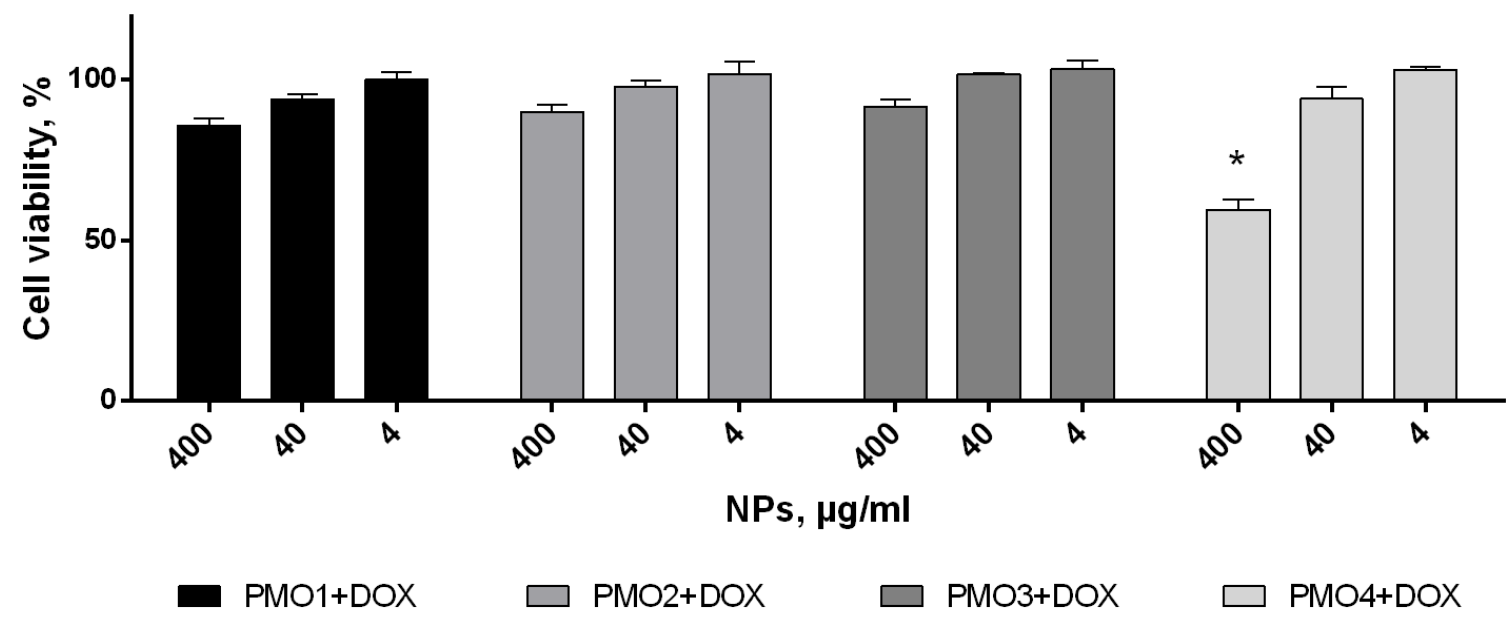

Figure S7. Cell viability studies of DOX-loaded PMO NPs on human glioblastoma U-87 MG cells (top) and human breast adenocarcinoma MCF-7 cells (bottom), $24 \mathrm{~h}$ incubation. Cells without any treatment were used as controls and taken as $100 \%$. MTT assay, the data are the mean $\pm \mathrm{SD}$ from at least three replicates. The cytotoxicity data for $400 \mu \mathrm{g} / \mathrm{mL}$ were compared with one-way ANOVA using multiple comparisons mode, ${ }^{*} \mathrm{p}<0.05$. 


\section{$1 \mathrm{~h}, \mathrm{MCF}-7$ cells}

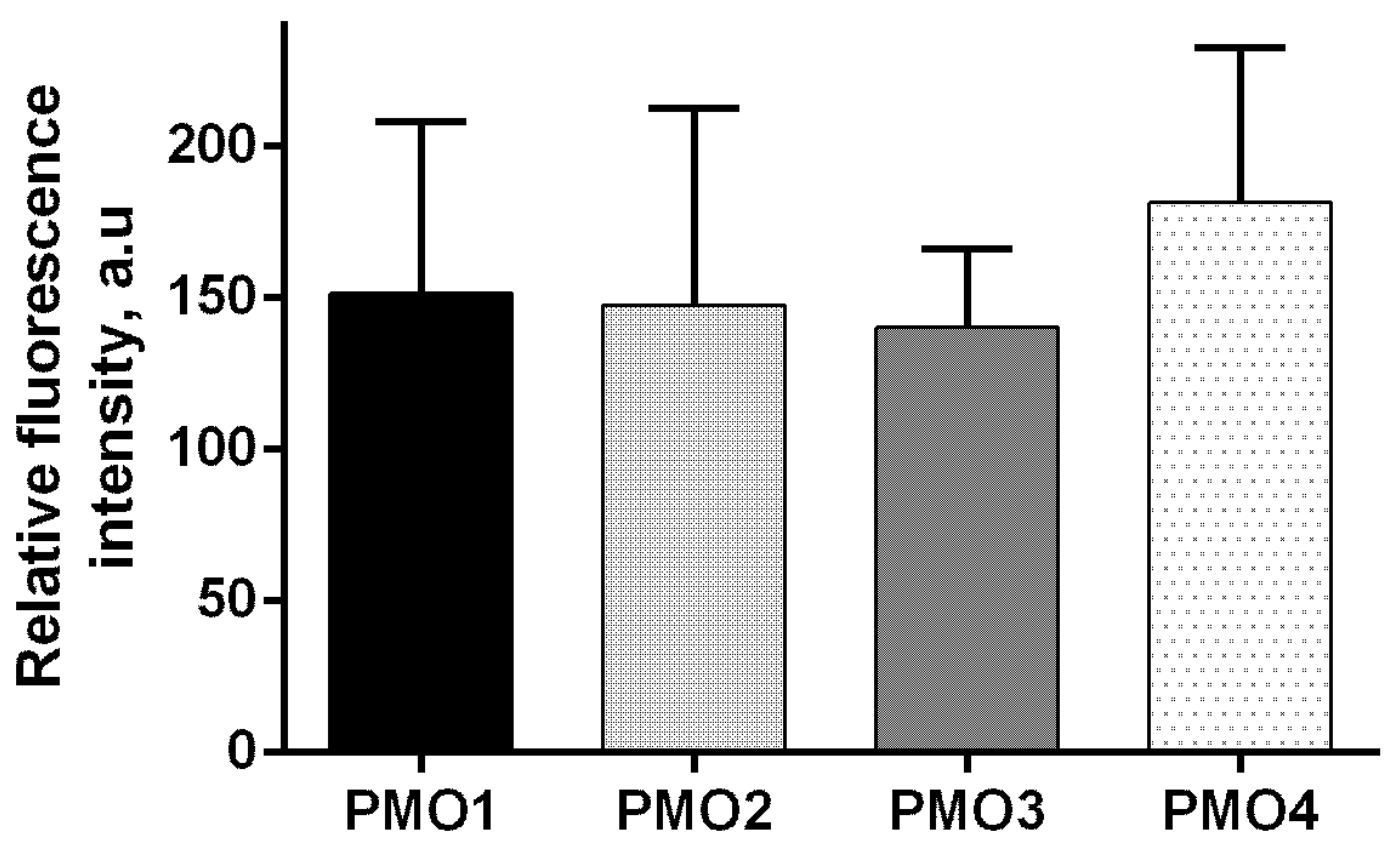

Figure S8: Uptake of PMOs co-loaded with DOX-RHD in human breast adenocarcinoma MCF$7,100 \mu \mathrm{g} / \mathrm{mL}, 1 \mathrm{~h}$ incubation. The data were obtained from confocal microscopy images; relative fluorescence intensity was measured using ImageJ software. Statistical analysis was performed using non-parametric Mann-Whitney test, $* * * p<0.001$. 

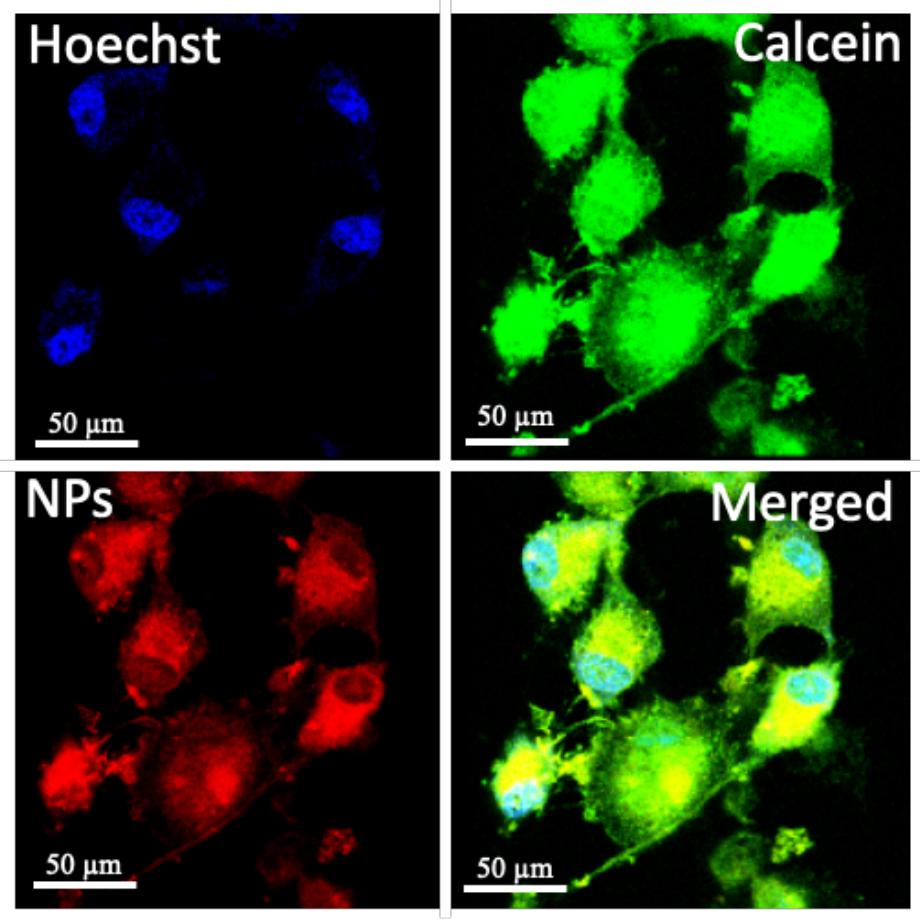

Figure S9: CLSM of U-87 MG cells incubated with $100 \mu \mathrm{g} / \mathrm{mL}$ PMO3-DOX-RHD for $1 \mathrm{~h}$. Nuclei stained with Hoechst (blue color), cytoplasm stained with calcein AM (green color), PMO NPs indicated in red color. Scale bar is $50 \mu \mathrm{m}$.

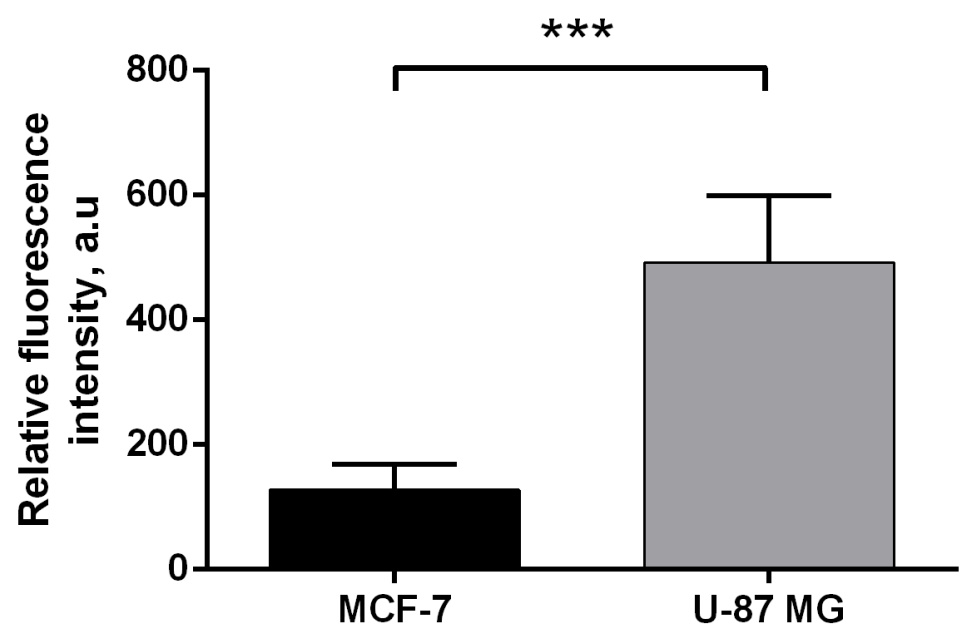

Figure S10: Uptake of PMO3-DOX-RHD in human breast adenocarcinoma MCF-7 and glioblastoma U-87 MG cells, $100 \mu \mathrm{g} / \mathrm{mL}, 1 \mathrm{~h}$ incubation. The data were obtained from confocal microscopy images; relative fluorescence intensity was measured using ImageJ software. Statistical analysis was performed using non-parametric Mann-Whitney test, ${ }^{* * *} \mathrm{p}<0.001$. 


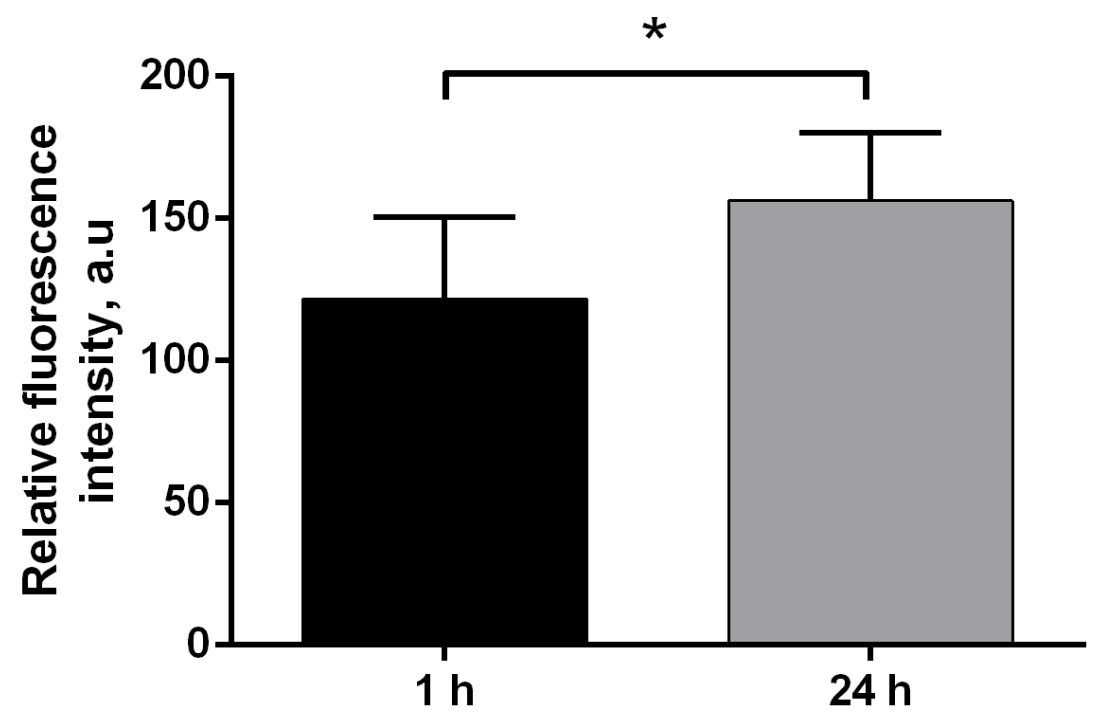

Figure S11: Uptake of PMO1-DOX in human breast adenocarcinoma MCF-7 cells, $100 \mu \mathrm{g} / \mathrm{mL}, 1$ $\mathrm{h}$ and $24 \mathrm{hrs}$ incubation. The data were obtained from confocal microscopy images; relative fluorescence intensity was measured using ImageJ software. Statistical analysis was performed using non-parametric Mann-Whitney test, ${ }^{*} \mathrm{p}<0.05$. 


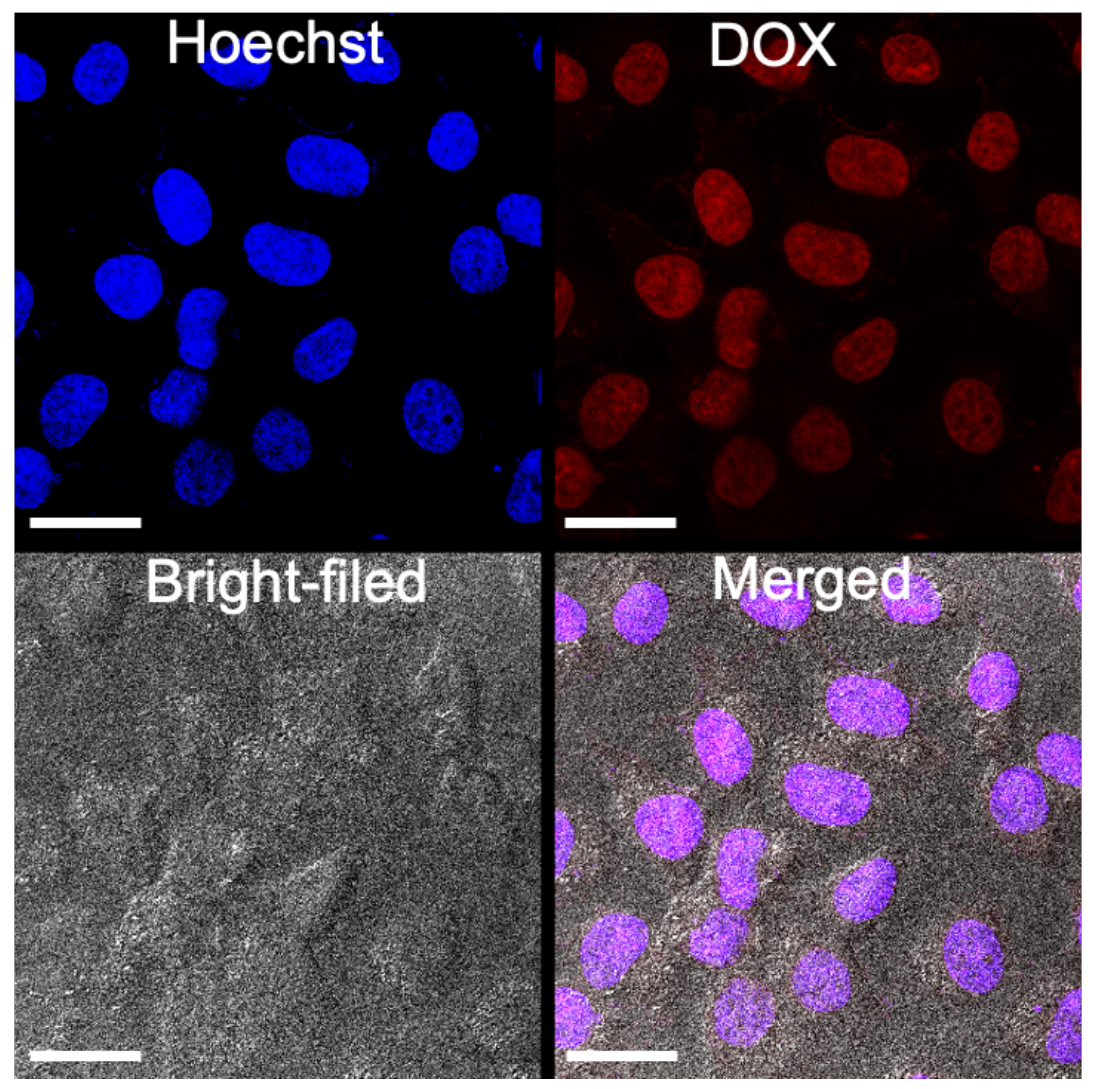

Figure S12: Confocal microscopy images of MCF-7 cell line incubated with free DOX staining $(20 \mu \mathrm{M})$ for $1 \mathrm{~h}$. Nuclei stained with Hoechst (blue color), DOX indicated in red color, and whiteblack image is the DIC image of the cells. Scale bar is $50 \mu \mathrm{m}$. 